ARTIGO ORIGINAL

\title{
Predição do teor de umidade de toras longas de madeira de Eucalyptus urophylla estocadas em pilhas ao ar livre
}

\author{
Predicting moisture content of long length log piles of Eucalyptus urophylla under \\ outdoor storage
}

Humberto de Jesus Eufrade-Junior ${ }^{1}$ (D), Sérgio Augusto Rodrigues ${ }^{1}$ (1), Emanuel Rangel Spadim ${ }^{1}$ (D), Saulo Philipe Sebastião Guerra ${ }^{1}$ (D), Adriano Wagner Ballarin ${ }^{1}$ (1)

${ }^{1}$ Universidade Estadual Paulista - UNESP. Botucatu, SP, Brasil

Como citar: Eufrade-Junior, H. J., Rodrigues, S. A., Spadim, E. R., Guerra, S. P. S., Ballarin, A. W. (2021). Predição do teor de umidade de toras longas de madeira de Eucalyptus urophylla estocadas em pilhas ao ar livre. Scientia Forestalis, 49(130), e3461. https://doi.org/10.18671/scifor.v49n130.03

\begin{abstract}
Resumo
Este trabalho teve como objetivo principal ajustar modelos de predição de umidade de toras com cerca de $6 \mathrm{~m}$ de comprimento de Eucalyptus urophylla empilhadas durante dois períodos - uma estação seca e outra chuvosa - no centro-sul do Estado de São Paulo. Para isso, a umidade foi estimada de forma indireta por meio da pesagem diária das pilhas em balanças fixas projetadas para esta finalidade ao longo de 160 dias de estocagem. No desenvolvimento das equações utilizou-se a técnica de regressão linear múltipla com a seleção de variáveis pelo método stepwise (passo a passo). Os modelos de predição de umidade mostraram que as variáveis umidade relativa do ar e o número de dias (tempo de estocagem), podem ser utilizadas para estimar o teor de umidade da madeira ( $\left.R^{2} a j .>92 \%\right)$. As toras estocadas durante o período denominado seco na região de estudo (542 mm de chuva) apresentaram uma umidade final menor - 31,1\% (base úmida) em relação às toras estocadas no período chuvoso (919 mm de chuva) com umidade final de $36,4 \%$ (base úmida).
\end{abstract}

Palavras-chave: Eucalyptus urophylla; Secagem ao ar; Variáveis meteorológicas; Estações do ano.

\begin{abstract}
The main objective of this work was to adjust moisture prediction models for logwood piles (6.2 $\mathrm{m}$ of length) of Eucalyptus urophylla stocked during two storage periods- a dry season and a rainy season - in the center-south of the State of São Paulo. For this purpose, the moisture content was indirectly estimated by daily weighing of the logs on fixed scales designed for this purpose during 160 days of storage. In the development of the equations, the multiple linear regression technique was used with stepwise selection of variables. The moisture prediction models showed that the variables, relative air humidity and number of days (storage time), can be used to estimate the moisture content of the wood ( $R^{2}$ aj.> 92\%). The logs stocked during the period called dry season in the study region (542 $\mathrm{mm}$ of rain) showed a lower final moisture content - $31.1 \%$ (wet basis) in relation to the logs stored in the rainy season (919 mm of rain) with final moisture content of $36.4 \%$ (wet basis).
\end{abstract}

Keywords: Eucalyptus urophylla; Air-drying; Meteorological variables; Seasons of the year.

\section{INTRODUÇÃO}

A madeira está presente em diversos segmentos, na construção civil e movelaria, uso náutico, conversão em produtos químicos e bioengenharia, papel e celulose, na siderurgia, na fabricação de painéis de madeira e para bioenergia (lenha, carvão, briquetes e pellets). No Brasil, as plantações florestais de eucalipto ocupam 5,7 milhões de hectares e representam mais de 75,1\% da produção

Fonte de financiamento: Conselho Nacional de Desenvolvimento Científico e Tecnológico (CNPq) - processo número 140145/2017-6.

Conflito de interesse: Nada a declarar.

Autor correspondente: hdjejunior@gmail.com

Recebido: 31 setembro 2019.

Aceito: 15 maio 2020

Editor: Paulo Henrique Müller Silva.

(c) (i) Este é um artigo publicado em acesso aberto (Open Access) sob a licença Creative Commons Attribution, que permite uso, distribuição e reprodução c) em qualquer meio, sem restrições desde que o trabalho original seja corretamente citado. 
madeireira para indústria, o que equivale a 166,0 milhões de $\mathrm{m}^{3}$ de madeira, sendo a espécie mais importante do setor (Indústria Brasileira de Árvores, 2019).

O teor de umidade é uma das propriedades físicas mais importantes para o aproveitamento da madeira, tanto na produção de papel, celulose e painéis de madeira, quanto na de carvão e lenha (Resende et al., 2018; Vinha Zanuncio et al., 2015; Brand; Muñiz, 2012). As toras recém-abatidas de eucalipto possuem elevada umidade (de 50 a 60\% - base úmida), o que significa dizer que tem esse percentual de seu peso total representado por água. Como estratégia para diminuir os custos de transporte, são normalmente empilhadas e estocadas no campo, por período variável, dependendo das condições climáticas do local ou outros condicionantes operacionais, como a distância de transporte e a demanda da fábrica (Sosa et al., 2015; Bergman, 2010). No geral, as toras entregues à indústria após a estocagem ao ar livre e sem cobertura, têm umidade (base úmida) de 25 a 35\%, mesmo após esse período de secagem.

Sabe-se que a umidade da madeira é influenciada pela espécie, densidade, características anatômicas, cerne e alburno (Kollmann \& Côté, 1968; Galvão \& Jankowsky, 1988). Na etapa de estocagem, a redução do teor de umidade na madeira é influenciada pelo diâmetro e pelo comprimento das toras (Abrahão et al., 2016), e condições de estocagem (empilhamento e cobertura), e da presença de casca (Rezende et al., 2010; Vinha Zanuncio et al., 2015), além das condições meteorológicas (Brand \& Muñiz, 2012). Quanto aos fatores climatológicos, a umidade relativa e a temperatura têm um papel importante pois influenciam diretamente a umidade de equilíbrio higroscópico da madeira (Jankowsky, 1990).

Na secagem da madeira são caracterizados dois fluxos de saída de água, que acontecem de forma simultânea durante o processo. Inicialmente, a redução da umidade acontece predominantemente pelo movimento capilar, ou seja, pela saída de água livre ou capilar até o ponto de saturação das fibras (PSF) e, posteriormente, há a saída da água higroscópica ou de impregnação (adsorvida às paredes celulares) pelo movimento de difusão (Kollmann \& Côté, 1968; Skaar, 1972; Galvão \& Jankowsky, 1988). Embora não seja uma regra, as espécies com menor densidade tendem a secar mais rapidamente do que as espécies mais densas, porque nelas a estrutura da madeira é normalmente mais permeável e contém mais espaços por unidade de volume; sendo que a água se move mais rapidamente através dos espaços vazios inter e intracelulares do que através das pontoações nas paredes celulares (Bergman, 2010). O processo de secagem é dificultado pela presença de cerne, principalmente devido à obstrução dos vasos por tilos (Galvão \& Jankowsky, 1988). A permeabilidade a líquidos do alburno na direção longitudinal às fibras é muito superior à do cerne (Silva et al., 2010).

Alguns estudos de secagem de toras em condições de clima temperado vêm conseguindo predizer a umidade da madeira com valores de coeficiente de determinação acima de $90 \%$ e erro padrão da estimativa abaixo de $2 \%$ com o uso de regressões lineares múltiplas (Erber et al., 2014; Erber et al., 2017; Sikanen et al., 2012) e não lineares (Kim \& Murphy, 2013; Murphy et al., 2012). Assim, o ajuste de modelos de regressão com preditores meteorológicos se consolida como uma ferramenta de tomada de decisão durante o planejamento da cadeia de operações florestais.

No Brasil, a maioria dos trabalhos de monitoramento da umidade de toras ao ar livre foi realizado por meio da pesagem contínua e individual de toras curtas, com comprimento variando entre 1 m e 3,6 m (Zanuncio et al., 2014; Rezende et al., 2010; Resende et al., 2018), procedimento que seria de difícil aplicação em estudo semelhante para toras longas (acima de 6,0m), que tem suas curvas de secagem ainda pouco conhecidas. Assim, este estudo teve como objetivo modelar o teor de umidade médio de toras longas de Eucalyptus urophylla empilhadas e estocadas ao ar livre em diferentes períodos do ano, uma época seca e outra chuvosa, no centro-sul do Estado de São Paulo.

\section{MATERIAL E MÉTODOS}

\section{Caracterização da floresta e das pilhas de toras}

Para o estudo foram utilizadas árvores de uma plantação clonal de eucalipto (Tabela 1) na Fazenda Experimental Lageado da Faculdade de Ciências Agronômicas (FCA/UNESP), no centro-sul do Estado de São Paulo, na cidade de Botucatu. A plantação de eucalipto 
(coordenadas $22^{\circ} 48^{\prime} 13^{\prime \prime} \mathrm{S}$ e $48^{\circ} 25^{\prime} 47^{\prime \prime} \mathrm{O}$ ) está situada em região com precipitação média de $1400 \mathrm{~mm} \mathrm{ano}^{-1}$, temperatura do ar média de $20^{\circ} \mathrm{C}$ e a $727 \mathrm{~m}$ de altitude. $\mathrm{O}$ solo do local foi caracterizado como Nitossolo vermelho com textura argilosa.

Tabela 1: Características da plantação florestal.

\begin{tabular}{lcc}
\multicolumn{2}{c}{ Características } & Unidade \\
\hline Espécie & & \\
Clone & Eucalyptus urophylla S.T. Blake \\
Idade & anos & AEC 0144 \\
Espaçamento de plantio & $\mathrm{m}$ & 7 \\
Densidade de plantio & árvores ha ${ }^{-1}$ & $3 \times 2$ \\
Altura média & $\mathrm{m}$ & 1667 \\
DAP médio & $\mathrm{cm}^{2}$ & 21,7 \\
IMA & $\mathrm{m}^{3} \mathrm{ha}^{-1} \mathrm{ano}^{-1}$ & 16,9 \\
\hline
\end{tabular}

DAP - diâmetro a altura do peito; IMA - Incremento médio anual.

Ao todo, foram colhidas 60 árvores com auxílio de motosserra e foram desdobradas em três ou quatro toras com 6,2 $\mathrm{m}$ de comprimento cada uma, respeitando-se o diâmetro comercial mínimo de $5 \mathrm{~cm}$ e mantendo-se a casca. Na montagem das pilhas, as toras foram distribuídas aleatoriamente e sem controle do diâmetro para simulação de uma operação comercial.

As toras utilizadas neste estudo fizeram parte de um trabalho maior, que envolveu a busca de uma cadeia de operações de base florestal menos onerosa para a bioenergia (Eufrade-Junior, 2019), portanto a madeira estocada foi posteriormente cavaqueada e utilizada na forma de cavacos para queima direta numa termelétrica.

\section{Monitoramento da umidade das pilhas de madeira}

Para o monitoramento contínuo da umidade das pilhas de madeira, foram construídas quatro pilhas de madeira, sendo que cada uma foi montada sobre uma balança composta de estrutura metálica e células de carga, especialmente projetada para esta pesquisa. A estrutura metálica foi dimensionada para suportar $8000 \mathrm{kgf}$ e recebeu, em cada um de seus vértices, uma célula de carga de 2000 kgf (modelo Cl2000, marca Líder), apoiada sobre uma base de concreto (Figura 1). O limite máximo de carga foi definido pelo volume estéreo, projetado inicialmente para $6 \mathrm{st} \mathrm{(metro} \mathrm{estéreo)} \mathrm{que} \mathrm{equivale} \mathrm{próximo} \mathrm{a} 4 \mathrm{~m}^{3}$ de madeira sólido, com base em outros estudos referenciais, sobretudo em países nórdicos (Röser et al., 2011; Sikanen et al. 2012; Visser et al., 2014).

As balanças foram montadas na área externa do Laboratório Agroflorestal de Biomassa

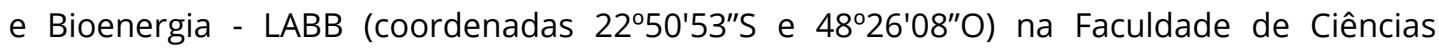
Agronômicas (FCA/UNESP) em Botucatu-SP. As pilhas de toras longas com casca foram dispostas na direção leste-oeste e submetidas a secagem ao ar livre e descobertas.

O acompanhamento da secagem das pilhas de madeira foi realizado em dois períodos, um seco, que compreendeu as estações outono e inverno, e outro chuvoso, que compreendeu as estações primavera e verão. A estocagem no período seco teve início no dia 05 de abril de 2017 e foi finalizada no dia 12 de setembro de 2017, totalizando 160 dias. As pilhas do período chuvoso foram estabelecidas no dia 27 de setembro de 2017 e desmontadas no dia 06 de março de 2018, também monitorada por 160 dias.

As dimensões das toras de madeira e outros parâmetros das pilhas após instalação do experimento para cada período avaliado estão apresentados na Tabela 2. 

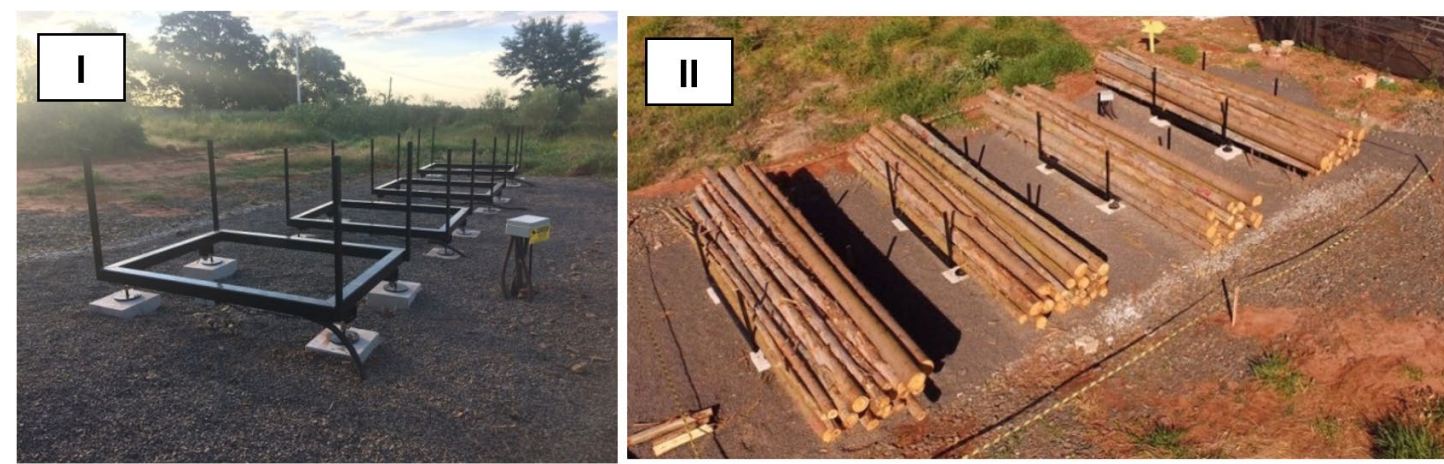

Figura 1: Pilhas de madeira para acompanhamento da curva de secagem durante o período de estocagem.

Tabela 2: Informações das pilhas de toras de madeira com casca acompanhadas nos períodos seco (outono-inverno) e chuvoso (primavera-verão).

\begin{tabular}{|c|c|c|c|c|c|}
\hline \multirow{2}{*}{ Parâmetros } & \multirow{2}{*}{ Unidade } & \multicolumn{4}{|c|}{ Pilhas } \\
\hline & & 1 & 2 & 3 & 4 \\
\hline \multicolumn{6}{|l|}{ Período seco (outono-inverno) } \\
\hline Dimensões (comp. $\times$ larg. $\times$ altura) & $\mathrm{m}$ & \multicolumn{4}{|c|}{$6,2 \times 1,5 \times 0,6$} \\
\hline Total do número de toras & - & 20 & 24 & 23 & 25 \\
\hline Peso úmido inicial das pilhas & $\mathrm{kg}$ & 3210 & 3252 & 3225 & 3271 \\
\hline Comprimento médio das toras & $\mathrm{m}$ & 6,2 & 6,3 & 6,2 & 6,3 \\
\hline Diâmetro com casca médio das toras & $\mathrm{cm}$ & 17,1 & 15,4 & 15,6 & 14,7 \\
\hline Volume de madeira sólido & $\mathrm{m}^{3}$ & 2,96 & 3,04 & 3,02 & 2,95 \\
\hline Teor de Umidade inicial da pilha (base úmida) & $\%$ & 53,8 & 54,3 & 54,3 & 54,5 \\
\hline Teor de Umidade final da pilha (base úmida) & $\%$ & 31,8 & 29,9 & 32,8 & 30,2 \\
\hline \multicolumn{6}{|l|}{ Período chuvoso (primavera-verão) } \\
\hline Dimensões (comp. $\times$ larg. $\times$ altura) & $\mathrm{m}$ & \multicolumn{4}{|c|}{$6,2 \times 1,5 \times 0,6$} \\
\hline Total do número de toras & - & 26 & 26 & 26 & 25 \\
\hline Peso úmido inicial das pilhas & $\mathrm{kg}$ & 3095 & 3084 & 2720 & 2775 \\
\hline Comprimento médio das toras & $\mathrm{m}$ & 6,1 & 6,1 & 6,0 & 6,1 \\
\hline Diâmetro com casca médio das toras & $\mathrm{cm}$ & 14,7 & 14,8 & 13,7 & 14,6 \\
\hline Volume de madeira sólido & $\mathrm{m}^{3}$ & 2,82 & 2,83 & 2,36 & 2,67 \\
\hline Teor de Umidade inicial da pilha (base úmida) & $\%$ & 53,1 & 55,0 & 54,2 & 53,4 \\
\hline Teor de Umidade final da pilha (base úmida) & $\%$ & 34,7 & 38,6 & 36,7 & 35,6 \\
\hline
\end{tabular}

O teor de umidade médio referencial das pilhas no início da estocagem foi avaliado com a retirada de discos de madeira com casca, de no mínimo $5 \mathrm{~cm}$ de espessura, das duas extremidades de todas as toras, após o corte das árvores e imediato desdobro destas no campo, antes da montagem das pilhas no pátio de secagem. Este parâmetro, calculado por meio da média de todos os discos foi imprescindível para a estimativa da massa seca de cada pilha (ms) e para a estimativa indireta da variação diária do teor de umidade (U) por meio da pesagem nas balanças durante o período de estocagem (mu) - Equação 1. O teor de umidade foi determinado e reportado na base úmida.

$U=\frac{m u-m s}{m u} \times 100$

Em que,

UB - Umidade das pilhas de madeira (base úmida) no dia, \%;

mu - Massa úmida das pilhas de madeira no dia aferida nas balanças, kg;

ms - Massa seca das pilhas de madeira estimadas no momento da estocagem, kg. 


\section{Modelos de predição da umidade da madeira e dados meteorológicos}

Para o desenvolvimento dos modelos de predição de umidade das pilhas de madeira foram levadas em consideração variáveis meteorológicas (precipitação pluviométrica, temperatura do ar, velocidade do vento, umidade relativa do ar e radiação solar), o tempo de estocagem (números de dias) e uma variável categórica (dummy). A variável categórica dummy foi inserida no modelo a fim de considerar os efeitos dos períodos de secagem estudados. Para o período seco (outono/inverno) foi atribuído um valor igual a 1, já para o período chuvoso (primavera/verão) foi considerado o valor de 0.

Para coleta das variáveis meteorológicas do modelo foram utilizadas leituras diárias de uma estação automática (marca Campbell Scientific Inc., modelo CR23X) localizada a $430 \mathrm{~m}$ da área experimental (coordenadas $22^{\circ} 50^{\prime} 49^{\prime \prime} \mathrm{S}$ e $48^{\circ} 25^{\prime}$ 52" O). Na Tabela 3 estão sumarizadas as condições meteorológicas médias dos períodos de estocagem.

Tabela 3: Condições meteorológicas da estocagem ao ar livre das pilhas de madeira durante cada período (seco e chuvoso) e suas respectivas estações do ano em Botucatu-SP.

\begin{tabular}{cccccccc}
\hline $\begin{array}{c}\text { Período de } \\
\text { estocagem }\end{array}$ & $\begin{array}{c}\text { Estação do } \\
\text { ano }\end{array}$ & ND & $\mathbf{P}(\mathbf{m m})$ & $\mathbf{T}\left({ }^{\circ} \mathbf{C}\right)$ & $\mathbf{V ~ ( \mathbf { m ~ s } ^ { - 1 } )}$ & UR (\%) & RS (MJ $\left.\mathbf{~ m}^{-2}\right)$ \\
\hline \multirow{2}{*}{ Seco } & Outono & 76 & 467,6 & 19,6 & 1,8 & 80,0 & 14,0 \\
& Inverno & 84 & 74,7 & 18,5 & 2,0 & 64,4 & 16,3 \\
\multirow{2}{*}{ Chuvoso } & Primavera & 84 & 413,5 & 21,9 & 2,1 & 74,5 & 19,5 \\
& Verão & 76 & 505,5 & 22,4 & 1,9 & 82,4 & 18,6 \\
\hline
\end{tabular}

U - Umidade das pilhas de madeira (base úmida), $\mathrm{V}$ - Velocidade média diária do vento, $\mathrm{T}$ - Temperatura média diária do ar, UR - Umidade relativa diária, RS - Radiação solar diária, P - Precipitação diária, ND - Número de dias de estocagem.

Utilizou-se a técnica de regressão linear múltipla com a seleção de variáveis pelo método stepwise (passo a passo) a partir de um modelo geral (Equação 2). Esse procedimento teve como objetivo obter um modelo minimizado com o melhor ajuste possível, selecionando as variáveis que tenham alta correlação com a variável resposta (umidade).

$U=$ Intercepto $+a \cdot V+b \cdot T+c . U R+d \cdot R S+e \cdot P+f . N D+g . D u m m y$

Em que,

UBU - Teor de Umidade das pilhas de madeira (base úmida), \%;

$\mathrm{V}$ - Velocidade média diária do vento, $\mathrm{m} \mathrm{s}^{-1}$;

$\mathrm{T}$ - Temperatura média diária do $\mathrm{ar},{ }^{\circ} \mathrm{C}$;

URA - Umidade relativa do ar diária, \%;

RS - Radiação solar diária, MJ m²;

$\mathrm{P}$ - Precipitação diária, $\mathrm{mm}$;

ND - Número de dias de estocagem, unidade;

Dummy - Valor 1 (período seco), valor 0 (período chuvoso);

$a, b, c, d, e, f, g$ - coeficientes da equação.

Estatisticamente as regressões, foram avaliadas pela normalidade dos resíduos (teste de Shapiro-Wilk; $p<0,05)$, pela não existência de autocorrelação (teste Durbin-Watson) considerando-se serem os dados provenientes de séries temporais e por fim, pelo coeficiente de determinação ajustado ( $\mathrm{R}^{2} \mathrm{aj} . \%$.) e erro padrão da estimativa ( $\left.\mathrm{S}_{\mathrm{yx}} \%\right)$. Todos os dados foram analisados no ambiente do software estatístico R (R Development Core Team, 2017).

\section{RESULTADOS E DISCUSSÃO}

A variação do teor de umidade médio das pilhas de madeira ao longo do tempo - curva de secagem - está apresentada na Figura 2. O período referido como seco para o local de 
estudo (precipitação acumulada de $542 \mathrm{~mm}$ ) foi aquele que proporcionou um menor teor de umidade final de $31,1 \pm 1,38 \%$; já o teor de umidade final do período chuvoso (precipitação acumulada de $919 \mathrm{~mm}$ ) foi de $36,4 \pm 1,67 \%$. Além disso a menor quantidade de chuvas propiciou uma perda de umidade mais uniforme no período seco.

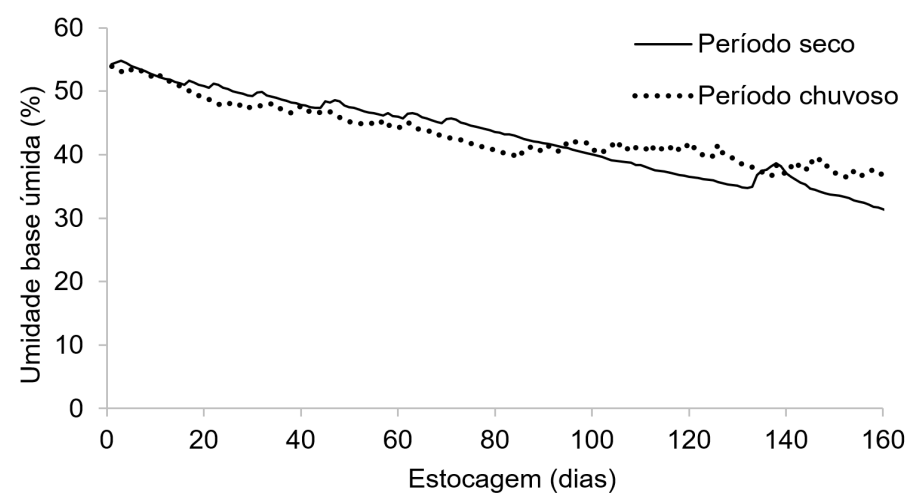

Figura 2: Comportamento da umidade média diária das pilhas de madeira ao longo da estocagem nos períodos seco (outono-inverno) e chuvoso (primavera-verão).

A inclinação da curva está intimamente relacionada com a taxa de secagem das pilhas e é maior à medida que aumenta a diferença de umidade entre a madeira e o ambiente. Essa inclinação tende a diminuir quando o teor de umidade da madeira se aproxima do teor de umidade de equilíbrio higroscópico (Jankowsky, 1990). Nas duas situações contempladas período seco e período chuvoso - não houve uma estabilização do teor de umidade das pilhas, o que pode ser atribuído às chuvas e a estocagem ao ar-livre sem cobertura.

A curva de secagem foi muito semelhante entre as repetições (pilhas), o que pode ser constatado pelo comportamento do desvio-padrão do monitoramento diário da umidade de cada período de estocagem (Figura 3). Os maiores valores de desvio-padrão para as épocas secas e chuvosas, foram de 1,40 e 1,68 pontos percentuais, respectivamente.
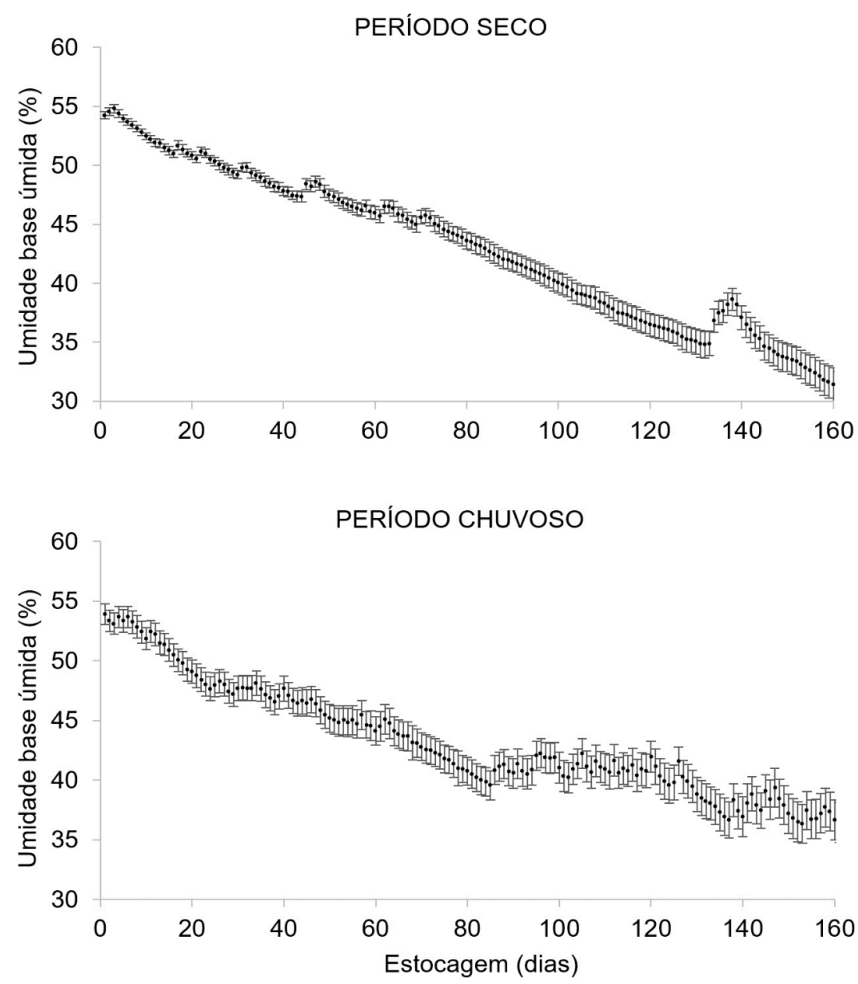

Figura 3: Comportamento do desvio-padrão da umidade média diária das pilhas estocadas nos períodos seco e chuvoso. 
Para um detalhamento maior, por estação do ano em cada período avaliado, as maiores taxas de secagem foram encontradas na primavera e no inverno, vide os maiores coeficientes angulares das retas apresentadas na Figura 4.

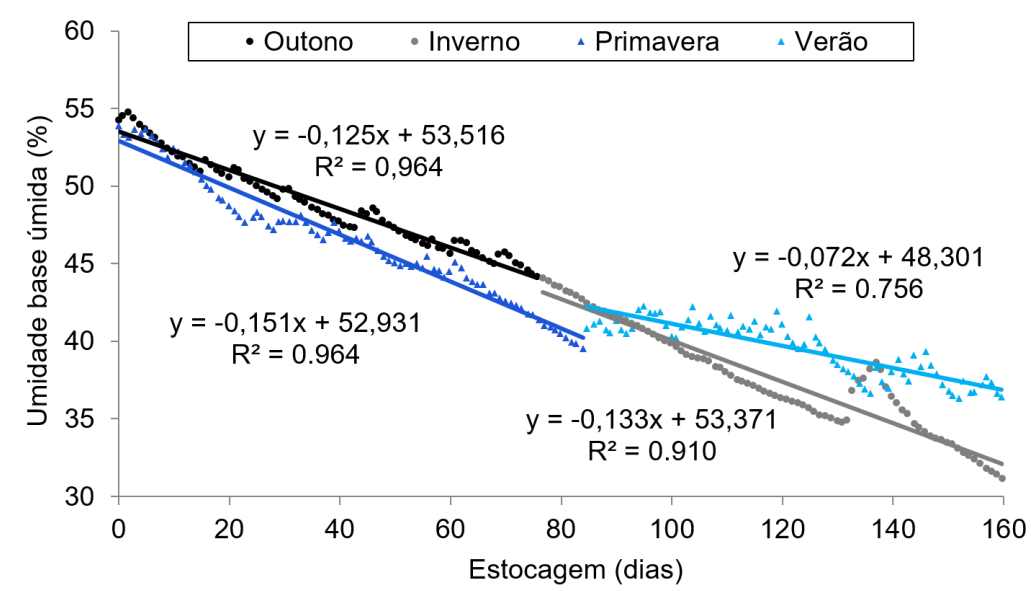

Figura 4: Curva de secagem das pilhas detalhada por estação do ano.

As taxas de redução de umidade foram de $0,125 \%$ dia $^{-1}$ no outono e $0,133 \%$ dia-1 no inverno, que caracterizaram o período seco. Já no período chuvoso, foi encontrada a taxa de secagem de $0,072 \%$ dia $^{-1}$ no verão e $0,151 \%$ dia $^{-1}$ na primavera. Para o ano e local avaliados, a estocagem poderia reduzir ainda mais a umidade da madeira se fosse realizada nas estações do inverno e primavera, com vantagens na cadeia de operações florestais, sobretudo no transporte da madeira à fábrica (Sosa et al., 2015; Acuna et al., 2012).

As taxas observadas são menores que as reportadas para toras curtas de eucalipto (menores que 3,6 m) estocadas no campo, de 0,109\% dia-1 a 0,286\% dia-1 (Rezende et al., 2010; Zanuncio et al., 2014). As diferenças podem ser explicadas pelo maior comprimento das toras avaliadas e as condições meteorológicas de cada local de estudo (Brand; Muñiz, 2012; Abrahão et al., 2016)

A fim de predizer o teor de umidade e avaliar as variáveis mais importantes na secagem das pilhas foram desenvolvidos dois modelos com suporte da análise de regressão stepwise (Tabela 4). O Modelo 1 foi aquele que a técnica apresentou como o ideal; o Modelo 2 foi testado considerando a variável ND (dias de estocagem) e a variável dummy para obter de maneira rápida uma estimativa do teor de umidade das pilhas em condições de campo.

Tabela 4: Coeficientes e estatística dos modelos de predição de umidade.

\begin{tabular}{|c|c|c|c|c|c|}
\hline Modelos & Coeficientes & & $p$-valor & 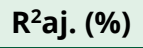 & Syx (\%) \\
\hline Modelo 1 & & & & 94,83 & 1,28 \\
\hline Intercepto & 43,341532 & * & $<2 \times 10^{-16}$ & & \\
\hline ND, dias & $-0,113080$ & * & $<2 \times 10^{-16}$ & & \\
\hline $\mathrm{T},{ }^{\circ} \mathrm{C}$ & 0,122077 & * & 0,000242 & & \\
\hline UR, \% & 0,070293 & * & $<2 \times 10^{-16}$ & & \\
\hline $\mathrm{RS}, \mathrm{MJ} \mathrm{m}^{-2}$ & 0,043435 & * & 0,012792 & & \\
\hline Dummy & 0,645593 & * & 0.002131 & & \\
\hline Modelo 2 & & & & 92,82 & 1,50 \\
\hline Intercepto & 52,393805 & * & $<2 \times 10^{-16}$ & & \\
\hline ND, dias & $-0,116012$ & * & $<2 \times 10^{-16}$ & & \\
\hline Dummy & $-0,284410$ & & 0,090400 & & \\
\hline
\end{tabular}

$\mathrm{R}^{2}$ aj. = coeficiente de determinação ajustado; Syx = erro padrão da estimativa; * = significativo a $5 \%(p<0,05)$ pelo Teste t-Student. 
O Modelo 1 apresentou o melhor desempenho na predição de umidade da madeira nas pilhas ( $R^{2}$ aj. de $94,8 \%$ e $S_{y x}$ de $1,3 \%$ ), seguido pelo Modelo 2 ( $R^{2}$ aj. de $92,8 \%$ e $S_{y x}$ de $1,5 \%$ ), ambos demonstrando uma grande eficiência na predição da umidade das pilhas estocadas.

As variáveis ND, T, UR e a dummy foram selecionadas como as que mais explicam a perda de umidade das toras durante a estocagem (Modelo 1), com destaque para o forte efeito das variáveis ND e UR. Nota-se que a UR teve um comportamento muito semelhante as duas curvas de secagem nos períodos estudados (Figura 5). De fato, a saída de água livre (movimento capilar) pode ter sido predominante na secagem das pilhas, sendo que foi fortemente influenciado pela umidade relativa do ar.
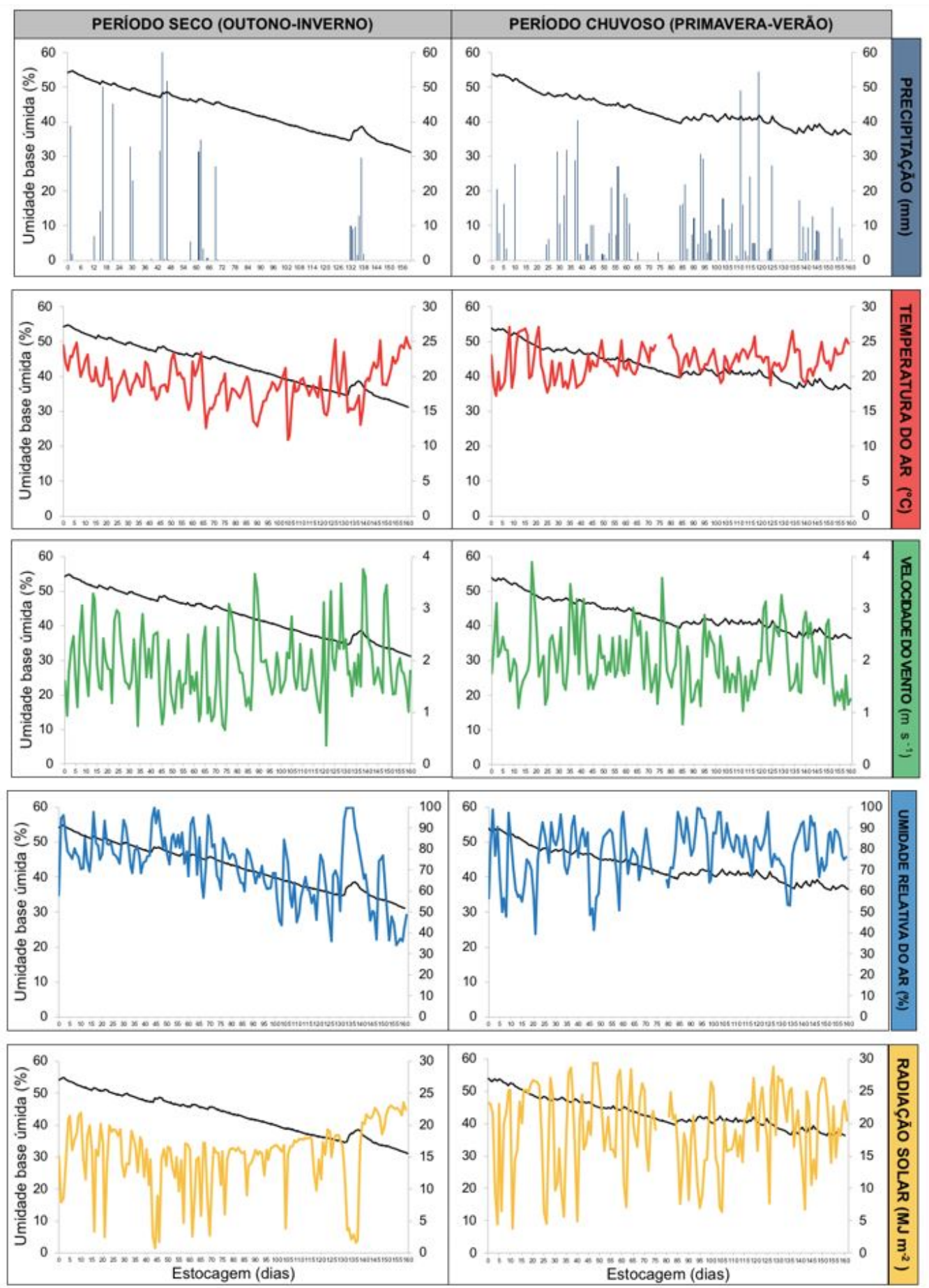

Figura 5: Curva de secagem das pilhas e condições meteorológicas durante os períodos de estocagem. 
Paradoxalmente, a técnica de regressão stepwise eliminou a variável P (precipitação) do Modelo 1. O efeito da precipitação parece ter sido minimizado pela casca. Observações de campo permitiram evidenciar o efeito protetor da casca na reabsorção de água durante e após as precipitações. Como já é conhecido que toras descascadas apresentam uma taxa de secagem maior (Rezende et al., 2010; Resende et al., 2018) sugere-se, de maneira mais ampla, que a casca tenha um efeito de amortecimento, suavizando as variações diárias (perdas e ganhos) de umidade ao longo da estocagem das toras ao ar livre.

Em situações rotineiras no campo o Modelo 2 mostra-se de grande utilidade para uma estimativa rápida da umidade média da madeira nas pilhas sem necessidade de quantificação de dados meteorológicos usando apenas as variáveis ND e dummy com uma precisão aceitável na localidade estudada.

As curvas estimadas pelos modelos para cada período de estocagem estão mostradas na Figura 6, ambas foram próximas e se ajustaram bem em relação à variável resposta.

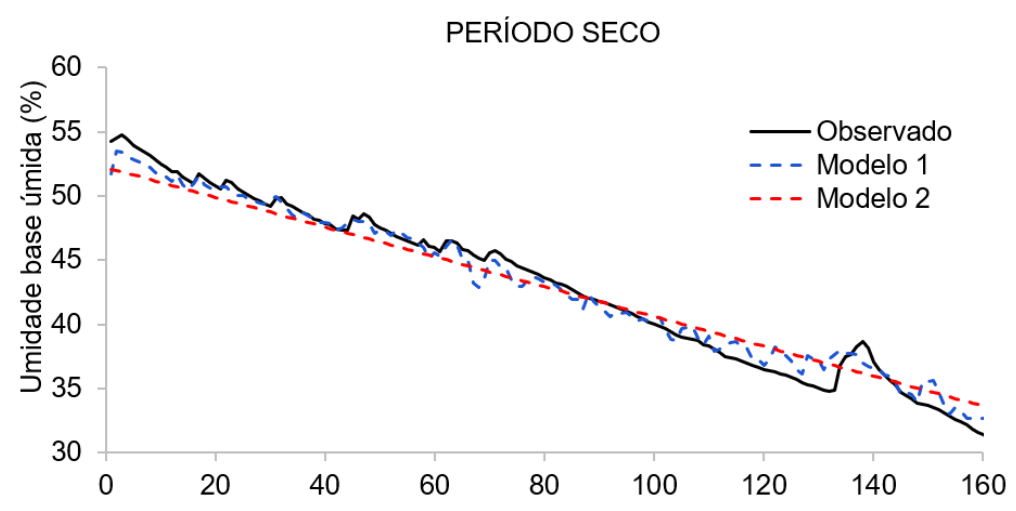

PERIODO CHUVOSO

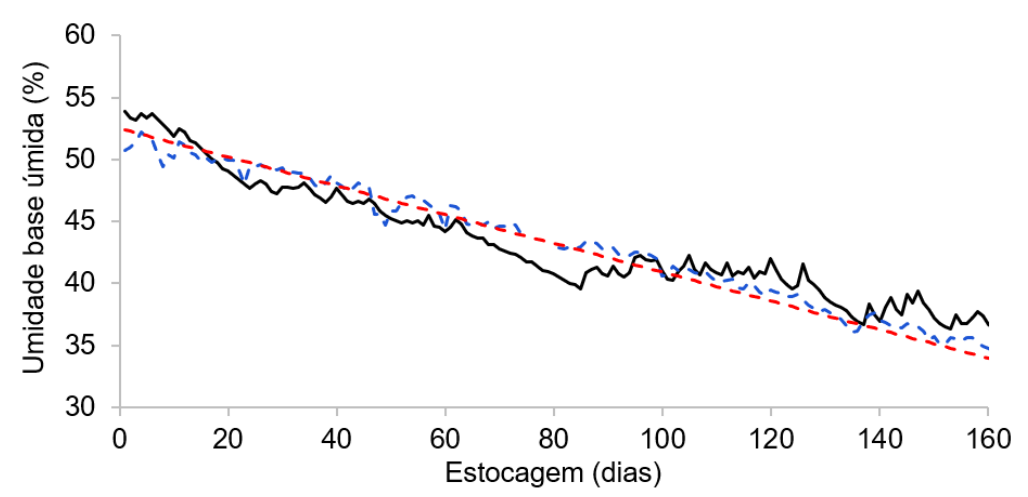

Figura 6: Curvas de secagem observadas e estimada para cada modelo de predição de umidade ajustado nos períodos estudados. O Modelo $1[\mathrm{U}=43,341532+0,122077 . \mathrm{T}+0,070293 . \mathrm{UR}+0,043435$. RS - 0,113080.ND + 0,645593.Dummy]; já o Modelo 2 [U=62,393805 - 0,116012.ND - 0,284410.Dummy]. Em que, $\mathrm{U}=$ teor de umidade das pilhas (\% base úmida); $\mathrm{T}=$ temperatura média diária do $\operatorname{ar}\left({ }^{\circ} \mathrm{C}\right)$; UR=Umidade relativa do ar diária (\%); RS=Radiação solar diária (MJ $\mathrm{m}^{-2}$ ); ND= Número de dias de estocagem (unidade); e Dummy = Valor 1 (período seco), valor 0 (período chuvoso).

O modelo 1 foi sensível aos picos de umidade por possuir uma regressão linear múltipla e atingiu em ambos os casos, o valor mais próximo da umidade final das pilhas. No modelo mais simplificado, por possuir uma variável numérica (ND) e outra categórica (dummy), o modelo 2 se comporta como uma reta (regressão linear simples).

Este experimento teve como premissa estudar o comportamento da umidade média da pilha de madeira e, portanto, este comportamento pode não representar a secagem individual de cada tora que compõe a pilha. As dimensões das toras e as posições que ocupam na pilha têm um grande efeito na perda de umidade. 


\section{CONCLUSÕES}

O Modelo 1 apresentou o melhor desempenho ( $R^{2}$ aj. de $94,8 \%$ e $S_{y x}$ de 1,3\%) na predição de umidade das toras de 6,2m de comprimento de Eucalyptus urophylla, sendo que a umidade relativa do ar (UR) e o número de dias (tempo de estocagem) foram as variáveis mais significativas no modelo.

As taxas de secagem foram diferentes para os períodos analisados, bem como para as estações do ano. As maiores perdas de umidade foram observadas no inverno e na primavera para o centro-sul do Estado de São Paulo.

\section{AGRADECIMENTOS}

Os autores agradecem o suporte do Conselho Nacional de Desenvolvimento Científico e Tecnológico (CNPq) por meio do financiamento da bolsa de pesquisa - processo número 140145/2017-6, à Faculdade de Ciências Agronômicas (FCA/UNESP), às Fazendas de Ensino, Pesquisa e Extensão (FEPE/FCA), ao Instituto de Pesquisa em Bioenergia (IPBEN/UNESP) e ao Laboratório Agroflorestal de Biomassa e Bioenergia (LABB/IPBEN) pelo apoio na condução das atividades de campo. Também, ao suporte das empresas - RJE lluminação, Sergomel Mecânica Industrial e Marrari Automação Industrial, na montagem e avaliação do experimento.

\section{REFERÊNCIAS}

Abrahão, C. P., Rocha, L. C. S., Paula, H., Trindade, E. G. B., Andrade, H. B., \& Santana, R. C. (2016). Efeito do diâmetro e do comprimento das toras na secagem de lenha de um clone de Eucalyptus urophylla × Eucalyptus camaldulensis. Scientia Forestalis, Piracicaba, 44(109), 85-93. http://dx.doi.org/10.18671/scifor.v44n109.08.

Acuna, M., Anttila, P., Sikanen, L., Prinz, R., \& Asikainen, A. (2012). Predicting and controlling moisture content to optimise forest biomass logistics. Croatian Journal of Forest Engineering, 33(2), 225-238.

Bergman, R. (2010). Chapter 13: Drying and control of moisture content and dimensional changes. In: Forest Products Laboratory. Wood handbook: wood as an engineering material (100th ed.). Madison: U.S. Dept. of Agriculture, Forest Service, Forest Products Laboratory.

Brand, M. A., \& Muñiz, G. I. B. (2012). Influência da época de colheita e da estocagem na composição química da biomassa florestal. Floresta e Ambiente, 19(1), 66-78. http://dx.doi.org/10.4322/floram.2012.008.

Kim, D.-W., \& Murphy, G. (2013). Forecasting air drying rates of small Douglas-fir and hybrid poplar stacked logs in Oregon, USA. International Journal of Forest Engineering, 24(2), 137-147. http://dx.doi.org/10.1080/14942119.2013.798132.

Eufrade-Junior, H. J. (2019). Predição e controle da umidade da madeira para otimização da cadeia produtiva de energia de eucalipto (Tese de doutorado). Universidade Estadual Paulista "Júlio de Mesquita Filho" (Unesp), Faculdade de Ciências Agronômicas, Botucatu, SP.

Erber, G., Routa, J., Wilhelmson, L., Raitila, J., Toiviainen, M., Riekkinen, J., \& Sikanen, L. (2014). A prediction model prototype for estimating optimal storage duration and sorting. Metla Working papers, 297, 76.

Erber, G., Holzleitner, F., Kastner, M., \& Stampfer, K. (2017). Impact of different time interval bases on the accuracy of meteorological data based drying models for oak (Quercus L.) logs stored in piles for energy purposes. Croatian journal for engineering, 38, 1-9.

Galvão, A. P. M., \& Jankowsky, I. P. (1988). Secagem racional da madeira (111 p.). São Paulo: Nobel. Indústria Brasileira de Árvores - IBÁ. (2019). Relatório 2019 (79 p.). Brasília: IBA.

Jankowsky, I. P. (1990). Fundamentos de secagem de madeiras (13 p.). Piracicaba: ESALQ.

Kollmann, F. F. P., \& Côté, W. A. (1968). Principles of wood sciences and technology (vol. 1.). Berlin: SpringerVerlag. http://dx.doi.org/10.1007/978-3-642-87928-9.

Murphy, G., Kent, T., \& Kofman, P. D. (2012). Modeling air drying of Sitka spruce (Picea sitchensis) biomass in off-forest storage yards in Ireland. Forest Products Journal, 62(6), 443-449. http://dx.doi.org/10.13073/FPJ-D-12-00096.1.

R Development Core Team. (2017). R: A language and environment for statistical computing. Vienna: $\mathrm{R}$ Foundation for Statistical Computing. Recuperado em 01 de maio de 2018, de http://www.Rproject.org/ 
Resende, T. R., Carneiro, A. C. O., Ferreira, R. A. D. C., Kuki, K. N., Teixeira, R. U., Zaidan, Ú. R., Santos, R. D., Leite, H. G., \& Resende, M. D. V. (2018). Air-drying of eucalypts logs: genetic variations along time and stem profile. Industrial Crops and Products, 124, 316-324. http://dx.doi.org/10.1016/j.indcrop.2018.08.002.

Rezende, R. N., Lima, J. T., Silva, J. R. M., Napoli, A., Andrade, H. B., \& Faria, A. L. R. (2010). Air drying of logs from an Eucalyptus urophylla clone for carbonization use. Cerne, 16(4), 565-572. http://dx.doi.org/10.1590/S0104-77602010000400016.

Röser, D., Mola-Yudego, B., Sikanen, L., Prinz, R., Gritten, D., Emer, B., Väätäinen, K., \& Erkkilä, A. (2011). Natural drying treatments during seasonal storage of wood for bioenergy in different European locations. Biomass and Bioenergy, 35(10), 4238-4247. http://dx.doi.org/10.1016/j.biombioe.2011.07.011.

Sikanen, L., Röser, D., Anttila, P., \& Prinz, R. (2012). Forecasting algorithm for natural drying of energy wood in forest storages. For Energy Observer, 27, 1-7.

Silva, M. R., Machado, G. O., Deiner, J., \& Calil Junior, C. (2010). Permeability measurements of Brazilian Eucalyptus. Materials Research, 13(3), 281-286. http://dx.doi.org/10.1590/S151614392010000300002.

Skaar, C. (1972). Water in wood (218 p.). Syracuse: Syracuse University Press.

Sosa, A., Acuna, M., Mcdonnell, K., \& Devlin, G. (2015). Controlling moisture content and truck configurations to model and optimise biomass supply chain logistics in Ireland. Applied Energy, 137, 338-351. http://dx.doi.org/10.1016/j.apenergy.2014.10.018.

Visser, R., Berkett, H., \& Spinelli, R. (2014). Determining the effect of storage conditions on the natural drying of radiata pine logs for energy use. New Zealand Journal of Forestry Science, 44(3), 3. http://dx.doi.org/10.1186/1179-5395-44-3.

Zanuncio, A. J. V., Lima, J. T., Monteiro, T. C., Trugilho, P. F., \& Lima, F. S. (2014). Secagem ao ar livre da madeira para produção de carvão vegetal. Floresta e Ambiente, 21(3), 401-408. http://dx.doi.org/10.1590/2179-8087.028713.

Zanuncio, A. J. V., Carvalho, A. G., Silva, L. F., Lima, J. T., Trugilho, P. F., \& Silva, J. R. M. (2015). Predicting moisture content from basic density and diameter during air drying of Eucalyptus and Corymbia logs. Maderas. Ciencia y Tecnología, 17, 335-344. http://dx.doi.org/10.4067/S0718221X2015005000031.

Contribuição dos Autores: HJEJr.: conceituação, metodologia, investigação, escrita - primeira redação, curadoria dos dados, escrita - revisão e edição; SAR: curadoria dos dados, software, visualização, validação, escrita - revisão e edição; ERS: metodologia, escrita - revisão e edição; SPSG: administração do projeto, recursos, supervisão, escrita - revisão e edição; AWB: conceituação, administração do projeto, supervisão, escrita - revisão e edição. 